\title{
Anisotropy of acousto-optic figure of merit in tetragonal crystals with accounting for non-orthogonality of acoustic eigenwave polarizations. \\ 1. The cases of $\mathrm{KH}_{2} \mathrm{PO}_{4}$ and $\mathrm{NH}_{4} \mathrm{H}_{2} \mathrm{PO}_{4}$ crystals
}

\author{
Mys O., Kostyrko M., Adamenko D. and Vlokh R. \\ Vlokh Institute of Physical Optics, 23 Dragomanov Street, 79005 Lviv, Ukraine, \\ vlokh@ifo.lviv.ua
}

Received: 19.10 .2018

\begin{abstract}
In the present work we derive analytical relations for the effective elastooptic coefficients with accounting for the non-orthogonality of polarizations of the acoustic waves (AWs) in the crystals that belong to the symmetry groups $\overline{4} 2 \mathrm{~m}$, $4 / \mathrm{mmm}, 422$ and $4 \mathrm{~mm}$. We analyze anisotropies of acousto-optic (AO) figure of merit (AOFM) for $\mathrm{KH}_{2} \mathrm{PO}_{4}$ and $\mathrm{NH}_{4} \mathrm{H}_{2} \mathrm{PO}_{4}$ crystals within their crystallographic planes, which are derived under conditions when the $\mathrm{AW}$ non-orthogonality effect is neglected by or accounted for. We find that consideration of the angle of AW nonorthogonality changes significantly the AOFM values. AO diffraction geometries corresponding to maximums of AOFM are obtained for all of the nine types of AO interactions, including those concerned with the collinear diffraction. We demonstrate that the principal AOFM maximum for $\mathrm{NH}_{4} \mathrm{H}_{2} \mathrm{PO}_{4}$ is equal to $10.0 \times 10^{-15} \mathrm{~s}^{3} / \mathrm{kg}$. It can be achieved at the type II of AO interactions with the quasilongitudinal AW in the crystallographic plane $a b$. The highest AOFM value peculiar for the anisotropic $\mathrm{AO}$ diffraction in $\mathrm{NH}_{4} \mathrm{H}_{2} \mathrm{PO}_{4}, 9.5 \times 10^{-15} \mathrm{~s}^{3} / \mathrm{kg}$, can be reached at the type IX of $\mathrm{AO}$ interactions with a so-called $\mathrm{AW} \mathrm{QT}_{2}$ in the $a c$ plane. Finally, the highest AOFM found for the case of collinear diffraction, $4.4 \times 10^{-15} \mathrm{~s}^{3} / \mathrm{kg}$, is also inherent to the $\mathrm{NH}_{4} \mathrm{H}_{2} \mathrm{PO}_{4}$ crystals. $\mathrm{KH}_{2} \mathrm{PO}_{4}$ is characterized by somewhat lower AOFM values.
\end{abstract}

Keywords: acousto-optic figure of merit, anisotropy, tetragonal crystals, $\mathrm{KH}_{2} \mathrm{PO}_{4}$, $\mathrm{NH}_{4} \mathrm{H}_{2} \mathrm{PO}_{4}$, non-orthogonality of acoustic wave polarization

PACS: $78.20 . \mathrm{Hp}, 42.79 . \mathrm{Jq}$

UDC: $535.42,535.012 .2$

\section{Introduction}

A great number of efficient acousto-optic (AO) materials belong to the crystals of tetragonal system. One of these crystalline materials is paratellurite (the chemical formula $\mathrm{TeO}_{2}$ and the point symmetry group 422 [1]), of which AO figure of merit (AOFM) is as high as $1200 \times 10^{-15} \mathrm{~s}^{3} / \mathrm{kg}$ [2]. We remind that the AOFM is determined by the relationship $M_{2}=n^{6} p_{e f}^{2} / \rho v^{3}$, where $\rho$ denotes the material density, $n$ the refractive index, $p_{e f}$ the effective elasto-optic coefficient (EEC), and $v$ the velocity of the acoustic wave (AW). One of the crystals representing tetragonal AO materials is lithium tetraborate, $\mathrm{Li}_{2} \mathrm{~B}_{4} \mathrm{O}_{7}$ which is described by the point symmetry group $4 \mathrm{~mm}$. It is highly resistant to a high-power optical radiation, with the appropriate damage threshold being equal to $32.2 \mathrm{GW} / \mathrm{cm}^{2}$ (according to our measurements [3]) or even $40 \mathrm{GW} / \mathrm{cm}^{2}$ (according to the data of Ref. [4]). The above crystals are transparent in the deep ultraviolet spectral range down to $170 \mathrm{~nm}$ [4]. Hence, lithium tetraborate represents a promising AO material [5-8] for operating high-power 
optical radiation in the ultraviolet range. Following from the results of our study [8], its maximal AOFM can reach $3.44 \times 10^{-15} \mathrm{~s}^{3} / \mathrm{kg}$ in the visible spectral range. In principle, it can become still higher in the ultraviolet range due to dispersion of refractive indices and elasto-optic coefficients.

$\mathrm{KH}_{2} \mathrm{PO}_{4}(\mathrm{KDP})$ and $\mathrm{NH}_{4} \mathrm{H}_{2} \mathrm{PO}_{4}$ (ADP) crystals characterized by the point symmetry group $\overline{4} 2 \mathrm{~m}$ under normal conditions also seem to be efficient $\mathrm{AO}$ materials for the ultraviolet range and high-power optical radiation. These crystals are transparent down to 250 and $200 \mathrm{~nm}$, respectively [1]. As a result, their $\mathrm{AO}$ properties have attracted much attention associated with ultraviolet tunable AO filters [9-12]. As shown by the present authors, the maximal AOFM value for the KDP crystals is equal to $7.1 \times 10^{-15} \mathrm{~s}^{3} / \mathrm{kg}$ [13]. According to the literature data, the AOFM for the ADP crystals amounts to $6.43 \times 10^{-15} \mathrm{~s}^{3} / \mathrm{kg}$ [1]. However, the last values do not represent the maximal AOFMs possible for the above crystals.

In our previous works, we have developed an analytical method for the studies of AOFM anisotropy [8, 13-19]. Among the crystals of which AOFMs have been analyzed there are such tetragonal crystals as $\mathrm{KDP}, \mathrm{TeO}_{2}, \mathrm{Li}_{2} \mathrm{~B}_{4} \mathrm{O}_{7}$ and $\mathrm{NaBi}\left(\mathrm{MoO}_{4}\right)_{2}$. As a matter of fact, this analysis has been carried out under assumption that the acoustic eigenwaves are purely transverse or longitudinal. This approximation is valid only when the angle of polarization deviation from the purely longitudinal or transverse states is very small (see, e.g., Mys O et. al, 2018. Ukr. J. Phys. Opt. 19: 165). As shown in Ref. [20] for the alternative case, consideration of the deviation of AW polarizations from the purely longitudinal or transverse states changes essentially the relations for the EEC and, as result, affects the final AOFM values. As follows from the results [20], the analytical relations for the AOFM with accounting for the AW non-orthogonality can be obtained only under simplest conditions when the AWs propagate within the principal crystallographic planes. Otherwise, the Christoffell tensor contains more than one off-diagonal components and can be expressed in the coordinate eigensystem using numerical solutions only. Nonetheless, even the correct results obtained for the principal crystallographic planes would provide important possibilities to design $\mathrm{AO}$ devices with the maximal AOFM values. Our aim is to analyze the AOFM anisotropy in a number of tetragonal crystals such as $\mathrm{KDP}, \mathrm{TeO}_{2}, \mathrm{Li}_{2} \mathrm{~B}_{4} \mathrm{O}_{7}$ and $\mathrm{NaBi}\left(\mathrm{MoO}_{4}\right)_{2}$, while accounting properly for the AW non-orthogonality. Notice that the AOFM anisotropy in the ADP crystals is studied here for the first time. In the first part of this work, we report the results obtained for the KDP and ADP crystals. The second part of the present study will deal with the other tetragonal crystals mentioned above.

\section{Methods of analysis}

\subsection{Acoustic and optical properties of KDP and ADP crystals}

We remind the main properties of the KDP and ADP crystals, which are needed for our further analysis. KDP and ADP are optically uniaxial and negative at the room temperature. At the light wavelength $\lambda=632.8 \mathrm{~nm}$, the refractive indices are equal to $n_{o}=1.5073$ and $n_{e}=1.4668$ for KDP [21], and $n_{o}=1.53$ and $n_{e}=1.48$ [22] for ADP. The densities of the KDP and ADP crystals are equal to $\rho=2338 \mathrm{~kg} / \mathrm{m}^{3}$ and $\rho=1803 \mathrm{~kg} / \mathrm{m}^{3}$, respectively [1]. In our calculations, we use the elastic-stiffness coefficients of the KDP crystals obtained in Ref. [23] $\left(C_{11}=71.4 \pm 0.8\right.$, $C_{12}=-4.9 \pm 1.0, C_{13}=12.9 \pm 0.3, C_{33}=56.15 \pm 0.3, C_{44}=12.7 \pm 0.1$ and $\left.C_{66}=6.24 \pm 0.05 \mathrm{GPa}\right)$ and the elasto-optic coefficients determined in Ref. [24] ( $p_{11}=0.238 \pm 0.024, \quad p_{12}=0.249 \pm 0.013$, $p_{13}=0.242 \pm 0.012, \quad p_{31}=0.227 \pm 0.011, \quad p_{33}=0.242 \pm 0.024, \quad p_{44}=-0.021 \pm 0.0021 \quad$ and $\left.p_{66}=-0.068 \pm 0.003\right)$. For the ADP crystals, the elastic stiffness coefficients are equal to $C_{11}=62.0$, $C_{12}=-5.0, C_{13}=14.0, C_{33}=30.0, C_{44}=9.1$ and $C_{66}=6.1 \mathrm{GPa}$, while the elasto-optic coefficients 
amount to $p_{11}=0.319, p_{12}=0.277, p_{13}=0.169, p_{31}=0.197, p_{33}=0.167, p_{44}=-0.058$ and $p_{66}=-0.091$ [22]. All the optical data are taken for the same optical wavelength, $632.8 \mathrm{~nm}$.

Anisotropy of the AW velocities in crystals can be analyzed using the Christoffel equation [25]:

$$
C_{i j k l} m_{j} m_{k} p_{l}=\rho v^{2} p_{i}
$$

where $C_{i j k l}$ denote the components of elastic-stiffness tensor, $m_{j}$ and $m_{k}$ the components of the unit wave vector of $\mathrm{AW}$, and $p_{i}$ and $p_{l}$ the components of the unit vector of displacement. The angle of deviation of the acoustic polarization from a purely longitudinal type is calculated basing on the Christoffel equation [25]:

$$
\begin{aligned}
& \Delta=\zeta-\theta=\frac{1}{2} \arctan \frac{\left(C_{13}+C_{44}\right) \sin 2 \theta}{\left(C_{11}-C_{44}\right) \cos ^{2} \theta+\left(C_{44}-C_{33}\right) \sin ^{2} \theta}-\theta, \\
& \Delta=\zeta-\theta=\frac{1}{2} \arctan \left(\frac{C_{12}+C_{66}}{C_{11}-C_{66}} \tan 2 \theta\right)-\theta .
\end{aligned}
$$

Here Eqs. (2) and (3) concern respectively the $a c$ (or $b c$ ) and the $a b$ planes, $\theta$ implies the angle between the AW vector and the $a$ (or $b$ ) axis, and $\zeta$ the angle between the same axis and the displacement vector. The corresponding non-orthogonality of the quasi-transverse waves can, in principle, be calculated with the same formulae. The only difference is that an additive factor $90 \mathrm{deg}$ should be added to the r.-h. s. of Eqs. (2) and (3). As seen from Fig. 1, the dependences of the angle of non-orthogonality on the wave vector orientation for the both crystals are similar for the $a c$ plane and exactly the same for the $a b$ plane. This angle reaches very high values (e.g., $\sim 37 \mathrm{deg}$ ) in the $a b$ plane.
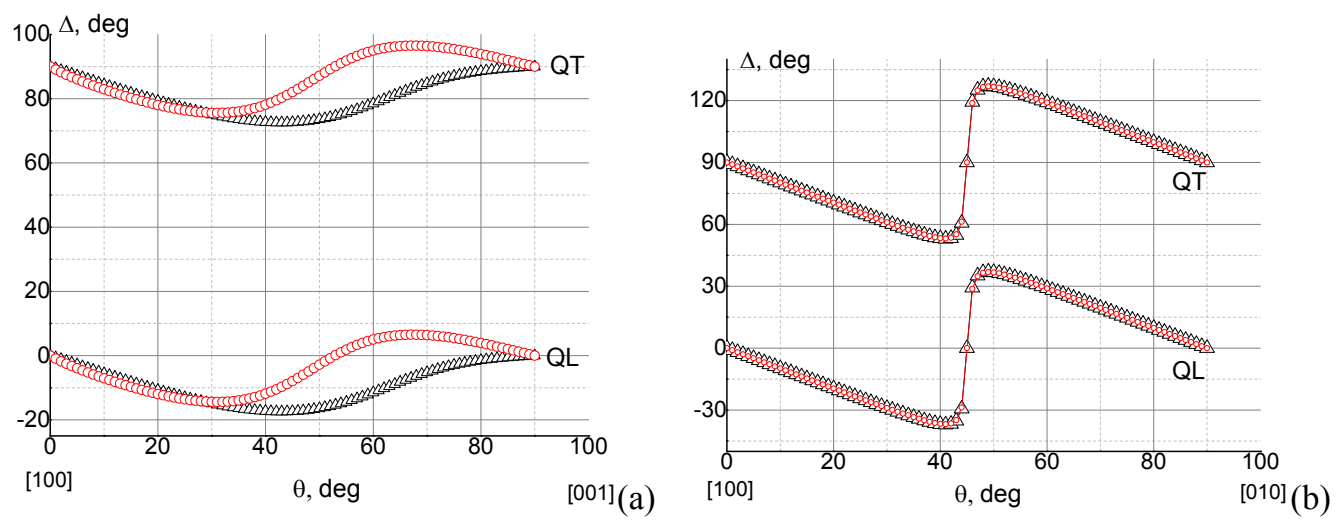

Fig. 1. Dependences of non-orthogonality angle on the AW vector orientation for KDP (circles) and ADP (triangles) crystals in the crystallographic planes $a c(a)$ and $a b$ (b).

The cross sections of the AW velocity surfaces are also similar for the KDP and ADP crystals (see Fig. 2 and Ref. [13] for the case of KDP). A schematic view of parts of the AW velocity surfaces, which are common for the both crystals, is presented in Fig. 3. There are five acoustic axes in the KDP and ADP crystals, which represent those propagation directions where the quasitransverse AWs have the same phase velocity.

One of the acoustic axis is parallel to the crystallographic axis $c$, while the four other lie in the $a b$ plane. The angular dependences of the AW velocities for the two quasi-transverse AWs for $\mathrm{KDP}$ and ADP touch each other in the principal $a b$ plane. For the KDP crystals, the points where 
these surfaces are touched lie at the angles $V_{1}=18.35 \mathrm{deg}+n \times 90 \mathrm{deg}$ and $V_{2}=71.65 \mathrm{deg}+n \times 90 \mathrm{deg}(n=0,1,2,3)$ with respect to the $a$ axis (see Fig. 2). For the ADP crystals, the corresponding angles are $V_{1}=13.90 \mathrm{deg}+n \times 90^{\circ}$ and $V_{2}=76.10 \mathrm{deg}+n \times 90^{\circ}$. In fact,
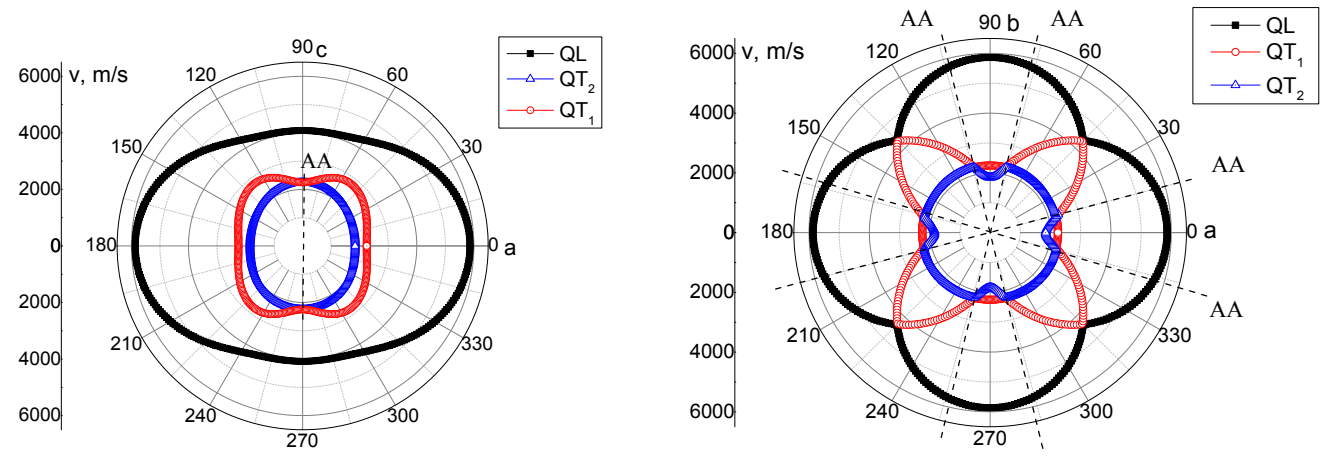

Fig. 2. Cross sections of $A W$ velocity surfaces by the principal crystallographic planes for $A D P$ crystals: $A A$ denote the acoustic axes and QL the quasi-longitudinal waves.

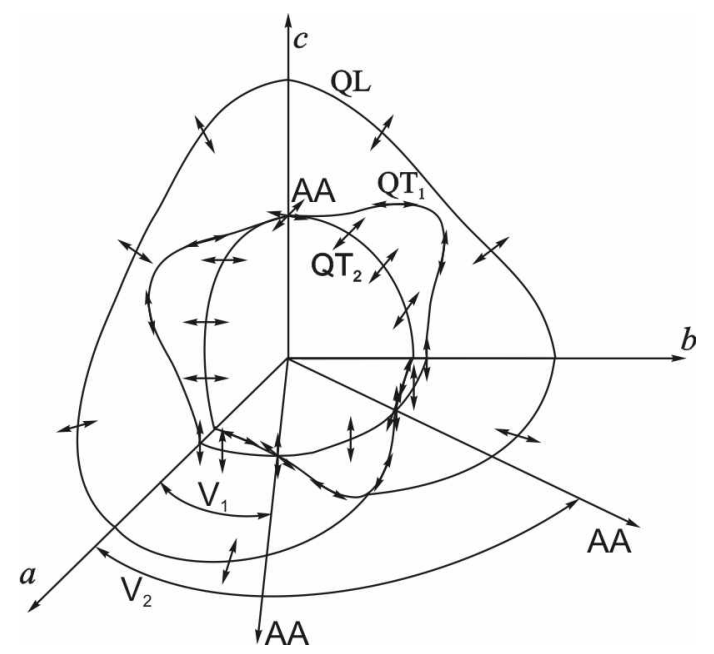

Fig. 3. Schematic view of parts of the AW velocity surfaces for ADP and KDP crystals.

the points mentioned above are nothing but polarization singularities, or topological defects of polarization orientation, with the strength equal to $1 / 2$. This means that the $\mathrm{AW}$ polarization in the $a b$ plane within the same AW velocity surface is switched by 90 deg when the wave vector crosses the acoustic axis direction. The acoustic axis parallel to the $c$ axis also represents the polarization singularity. However, the strength of the topological defect of polarization distribution is equal to 1 in the latter case.

\subsection{Relations for the EEC}

Using the procedures described in our recent work [20], one can derive the EEC for different types of AO interactions. In the mentioned work, the relations for the EEC have been obtained for the crystals of orthorhombic symmetry. These relations can be simplified for the tetragonal crystals that belong to the point symmetry groups $4 / \mathrm{mmm}, 4 \mathrm{~mm}, 422$ and $\overline{4} 2 \mathrm{~m}$, using the links among the elasto-optic coefficients $p_{11}=p_{22}, p_{12}=p_{21}, p_{13}=p_{23}, p_{31}=p_{32}$ and $p_{44}=p_{55}$ imposed by the higher crystal symmetry. 
The eigenvalues of the Christoffel equation can be found analytically only in case when the AWs propagate in the crystallographic planes. Thus, in the present work we consider the anisotropies of both the EEC and the AOFM only for the cases when the AWs propagate within the $a c$ and $a b$ planes. Notice that the EEC and AOFM anisotropies in the $b c$ and $a c$ planes are the same, due to symmetry conditions.

Let us consider the type $I$ of isotropic AO interactions of ordinary optical wave with a quasilongitudinal AW in the ac plane. With no accounting for polarization deviation from the purely longitudinal states, the EEC is written as

$$
p_{e f}^{(I)}=p_{12} \cos ^{2} \theta+p_{13} \sin ^{2} \theta .
$$

Taking such a deviation into account leads to a more complex relation,

$$
\begin{aligned}
p_{e f}^{(I)} & =p_{12}\left(\cos ^{2} \theta \cos (\theta-\zeta)-\sin 2 \theta \sin (\theta-\zeta)\right) \\
& +p_{13}\left(\sin ^{2} \theta \cos (\theta-\zeta)+\sin 2 \theta \sin (\theta-\zeta)\right)
\end{aligned}
$$

It is seen that Eq. (5) is reduced to Eq. (4) at $\zeta=\theta$. For the $a b$ plane the corresponding relations are given by

$$
\begin{gathered}
p_{e f}^{(I)}=\cos ^{2}\left(\theta+\theta_{B}\right)\left(p_{11} \cos ^{2} \theta+p_{12} \sin ^{2} \theta\right)+\sin ^{2}\left(\theta+\theta_{B}\right)\left(p_{12} \cos ^{2} \theta+p_{11} \sin ^{2} \theta\right), \\
-0.5 p_{66} \sin 2\left(\theta+\theta_{B}\right) \sin 2 \theta \\
p_{e f}^{(I)}=\cos ^{2}\left(\theta+\theta_{B}\right)\left\{\begin{array}{l}
\left(p_{11}\left(\cos ^{2} \theta \cos (\theta-\zeta)-\sin 2 \theta \sin (\theta-\zeta)\right)\right. \\
+p_{12}\left(\sin ^{2} \theta \cos (\theta-\zeta)+\sin 2 \theta \sin (\theta-\zeta)\right)
\end{array}\right\} \\
+\sin ^{2}\left(\theta+\theta_{B}\right)\left\{\begin{array}{l}
p_{12}\left(\cos ^{2} \theta \cos (\theta-\zeta)-\sin 2 \theta \sin (\theta-\zeta)\right) \\
+p_{11}\left(\sin ^{2} \theta \cos (\theta-\zeta)+\sin 2 \theta \sin (\theta-\zeta)\right)
\end{array}\right\} . \\
-p_{66} \sin 2\left(\theta+\theta_{B}\right)(\cos 2 \theta \sin (\theta-\zeta)+0.5 \sin 2 \theta \cos (\theta-\zeta))
\end{gathered}
$$

If we deal with the type $I I$ of $\mathrm{AO}$ interactions of extraordinary optical wave with a quasilongitudinal AW in the ac crystallographic plane, the EEC with no account for the polarization deviation from the purely longitudinal states can be presented as

$$
\begin{aligned}
p_{e f}^{(I I)} & =\cos ^{2}\left(\theta+\theta_{B}\right)\left(p_{11} \cos ^{2} \theta+p_{13} \sin ^{2} \theta\right)+\sin ^{2}\left(\theta+\theta_{B}\right)\left(p_{31} \cos ^{2} \theta+p_{33} \sin ^{2} \theta\right) . \\
& +0.5 p_{44} \sin 2\left(\theta+\theta_{B}\right) \sin 2 \theta
\end{aligned}
$$

The same relation written after considering properly for the deviation angle has the following form:

$$
\begin{aligned}
p_{e f}^{(I I)}= & \cos ^{2}\left(\theta+\theta_{B}\right)\left\{\begin{array}{l}
p_{11}\left(\cos ^{2} \theta \cos (\theta-\zeta)-\sin 2 \theta \sin (\theta-\zeta)\right) \\
+p_{13}\left(\sin ^{2} \theta \cos (\theta-\zeta)+\sin 2 \theta \sin (\theta-\zeta)\right)
\end{array}\right\} \\
& +\sin ^{2}\left(\theta+\theta_{B}\right)\left\{\begin{array}{l}
p_{31}\left(\cos ^{2} \theta \cos (\theta-\zeta)-\sin 2 \theta \sin (\theta-\zeta)\right) \\
+p_{33}\left(\sin ^{2} \theta \cos (\theta-\zeta)+\sin 2 \theta \sin (\theta-\zeta)\right)
\end{array}\right\} . \\
& +p_{44} \sin 2\left(\theta+\theta_{B}\right)(\cos 2 \theta \sin (\theta-\zeta)+0.5 \sin 2 \theta \cos (\theta-\zeta))
\end{aligned}
$$

These relations for the $a b$ plane read as

$$
\begin{aligned}
& p_{e f}^{(I I)}=p_{31}, \\
& p_{e f}^{(I I)}=p_{31} \cos (\theta-\zeta) .
\end{aligned}
$$


Now let us consider AO interactions with the quasi-transverse AWs. The main peculiarity of these waves is the existence of acoustic axes along the $c$ direction and in the $a b$ plane. Notice that the transverse waves can propagate with arbitrary polarization orientations along the acoustic axes. The types $I I I$ and $I V$ of AO interactions with a so-called $\mathrm{AW} \mathrm{QT}_{1}$ can be realized in the interaction plane $a c$. The EEC for the type $I I I$ of interactions of the ordinary optical wave is given by

$$
p_{e f}^{(I I I)}=\left(p_{12}-p_{13}\right) \sin 2 \theta,
$$

if one neglects the angle of non-orthogonality. If this angle is accounted for, one arrives at

$$
\begin{aligned}
p_{e f}^{(I I I)} & =p_{12}\left(\cos ^{2} \theta \cos (\zeta-\theta)-\sin 2 \theta \sin (\zeta-\theta)\right) \\
& +p_{13}\left(\sin ^{2} \theta \cos (\zeta-\theta)+\sin 2 \theta \sin (\zeta-\theta)\right)
\end{aligned} .
$$

It is evident that Eq. (13) reduces to Eq. (12) in the approximation of purely transverse AWs $(\zeta=270+\theta)$.

The type $I I I$ of AO interactions cannot be fulfilled in the $a b$ plane when the AW propagates at the angles $0 \mathrm{deg}<\theta<V_{1}$ and $V_{2}<\theta<90 \mathrm{deg}$ (i.e., in the first quadrant). The reason is that the appropriate elasto-optic coefficients are zero. However, the type III of AO interactions becomes possible when the AW propagates at the angles $V_{1}<\theta<V_{2}$ in the $a b$ plane. Then the EEC is equal to

$$
\begin{aligned}
p_{e f}^{(I I I)} & =p_{12}\left(\cos ^{2} \theta \cos (\zeta-\theta)-\sin 2 \theta \sin (\zeta-\theta)\right) \\
& +p_{13}\left(\sin ^{2} \theta \cos (\zeta-\theta)+\sin 2 \theta \sin (\zeta-\theta)\right)
\end{aligned}
$$

with no considering of the non-orthogonality and

$$
\begin{aligned}
p_{e f}^{(I I I)}= & \cos ^{2}\left(\theta+\theta_{B}\right)\left\{\begin{array}{l}
p_{11}\left(\cos ^{2} \theta \cos (\zeta-\theta)-\sin 2 \theta \sin (\zeta-\theta)\right) \\
+p_{12}\left(\sin ^{2} \theta \cos (\zeta-\theta)+\sin 2 \theta \sin (\zeta-\theta)\right)
\end{array}\right\} \\
& +\sin ^{2}\left(\theta+\theta_{B}\right)\left\{\begin{array}{l}
p_{12}\left(\cos ^{2} \theta \cos (\zeta-\theta)-\sin 2 \theta \sin (\zeta-\theta)\right) \\
+p_{11}\left(\sin ^{2} \theta \cos (\zeta-\theta)+\sin 2 \theta \sin (\zeta-\theta)\right)
\end{array}\right\} \\
& -p_{66} \sin 2\left(\theta+\theta_{B}\right)(0.5 \sin 2 \theta \cos (\zeta-\theta)+\cos 2 \theta \sin (\zeta-\theta)),
\end{aligned}
$$

with accounting for this effect.

For the type $I V$ of $\mathrm{AO}$ interactions of the extraordinary incident optical wave with the AW $\mathrm{QT}_{1}$, we obtain the EEC for the $a c$ plane of the form

$$
\begin{aligned}
p_{e f}^{(I V)}= & \cos ^{2}\left(\theta+\theta_{B}\right)\left(p_{11}-p_{13}\right) \sin 2 \theta+\sin ^{2}\left(\theta+\theta_{B}\right)\left(p_{31}-p_{33}\right) \sin 2 \theta \\
& +p_{44} \sin 2\left(\theta+\theta_{B}\right) \cos 2 \theta
\end{aligned}
$$

with no account of the non-orthogonality. Proper consideration of the non-orthogonality effect yields in

$$
\begin{aligned}
p_{e f}^{(I V)}= & \cos ^{2}\left(\theta+\theta_{B}\right)\left\{\begin{array}{l}
p_{11}\left(\cos ^{2} \theta \cos (\zeta-\theta)-\sin 2 \theta \sin (\zeta-\theta)\right) \\
+p_{13}\left(\sin ^{2} \theta \cos (\zeta-\theta)+\sin 2 \theta \sin (\zeta-\theta)\right)
\end{array}\right\} \\
& +\sin ^{2}\left(\theta+\theta_{B}\right)\left\{\begin{array}{l}
p_{31}\left(\cos ^{2} \theta \cos (\zeta-\theta)-\sin 2 \theta \sin (\zeta-\theta)\right) \\
+p_{33}\left(\sin ^{2} \theta \cos (\zeta-\theta)+\sin 2 \theta \sin (\zeta-\theta)\right)
\end{array}\right\} . \\
& +p_{44} \sin 2\left(\theta+\theta_{B}\right)(0.5 \sin 2 \theta \cos (\zeta-\theta)+\cos 2 \theta \sin (\zeta-\theta))
\end{aligned}
$$


The type $I V$ of $\mathrm{AO}$ interactions in the $a b$ interaction plane is impossible for the $\mathrm{AW}_{\mathrm{WT}}$ propagating at the angles $0 \operatorname{deg}<\theta<V_{1}$ and $V_{2}<\theta<90 \mathrm{deg}$ (i.e., in the first quadrant), since the appropriate elasto-optic coefficients are zero. This is no longer true when the AWs propagate in the $a b$ plane at the angles $V_{1}<\theta<V_{2}$. Then the type $I V$ of AO interactions can be fulfilled, and the EEC becomes as follows (note that the condition $p_{31}=p_{32}$ holds true):

$$
\begin{aligned}
& p_{e f}^{(I V)}=\left(p_{31}-p_{32}\right) \sin 2 \theta=0, \\
& p_{e f}^{(I V)}=p_{31} \cos (\zeta-\theta),
\end{aligned}
$$

Eqs. (18) and (19) refer respectively to the cases when the non-orthogonality effect is taken into account and neglected.

In the $a c$ crystallographic plane, the types $V$ and $V I$ of AO interactions with a so-called AW $\mathrm{QT}_{2}$ cannot be implemented for the crystals that belong to point group $\overline{4} 2 \mathrm{~m}$, since the appropriate elasto-optic coefficients are equal to zero. On the other hand, the type $V$ of AO interactions with the ordinary optical wave becomes possible in the $a b$ plane when the AW propagates at the angles in the first quadrant $\left(0 \operatorname{deg}<\theta<V_{1}\right.$ and $V_{2}<\theta<90 \mathrm{deg}$ ). Then the EEC reads as

$$
p_{e f}^{(V)}=\left(p_{11}-p_{12}\right) \sin 2 \theta \cos 2\left(\theta+\theta_{B}\right)+p_{66} \sin 2\left(\theta+\theta_{B}\right) \cos 2 \theta,
$$

and

$$
\begin{aligned}
p_{e f}^{(V)}= & \cos ^{2}\left(\theta+\theta_{B}\right)\left\{\begin{array}{l}
p_{11}\left(\cos ^{2} \theta \cos (\zeta-\theta)-\sin 2 \theta \sin (\zeta-\theta)\right) \\
+p_{12}\left(\sin ^{2} \theta \cos (\zeta-\theta)+\sin 2 \theta \sin (\zeta-\theta)\right)
\end{array}\right\} \\
& +\sin ^{2}\left(\theta+\theta_{B}\right)\left\{\begin{array}{l}
p_{12}\left(\cos ^{2} \theta \cos (\zeta-\theta)-\sin 2 \theta \sin (\zeta-\theta)\right) \\
+p_{11}\left(\sin ^{2} \theta \cos (\zeta-\theta)+\sin 2 \theta \sin (\zeta-\theta)\right)
\end{array}\right\} \\
& -p_{66} \sin 2\left(\theta+\theta_{B}\right)(0.5 \sin 2 \theta \cos (\zeta-\theta)+\cos 2 \theta \sin (\zeta-\theta)),
\end{aligned}
$$

when the non-orthogonality effect is respectively neglected by and accounted for. The type $V$ of $\mathrm{AO}$ interactions is impossible when the AW propagates in the $a b$ plane at the angles $V_{1}<\theta<V_{2}$.

When the AW propagates at the angles $0 \operatorname{deg}<\theta<V_{1}$ and $V_{2}<\theta<90 \mathrm{deg}$ in the $a b$ plane, we obtain the $\operatorname{EEC}\left(p_{31}=p_{32}\right)$

$$
p_{e f}^{(V I)}=\left(p_{31}-p_{32}\right) \sin 2 \theta=0
$$

and

$$
p_{e f}^{(V I)}=p_{31} \cos (\zeta-\theta),
$$

which are valid for the cases of accounting for and neglecting by the non-orthogonality. The type $V I$ of AO interactions cannot be realized when the AW propagates in the $a b$ plane at the angles $V_{1}<\theta<V_{2}$.

Let us now consider the anisotropic AO diffraction. In the principal crystallographic planes, this diffraction can be implemented only with purely transverse AWs. The AO interactions with the purely transverse $\mathrm{AW} \mathrm{QT}_{2}$ become possible in the ac plane, and the interactions with the AWs $\mathrm{QT}_{1}$ or $\mathrm{QT}_{2}$ can be implemented in the $a b$ plane. In the latter case, we should deal with the propagation angles $0 \mathrm{deg}<\theta<V_{1}$ and $V_{2}<\theta<90 \mathrm{deg}$ for the $\mathrm{AW} \mathrm{QT}_{1}$ or the angles $V_{1}<\theta<V_{2}$ for the $\mathrm{AW} \mathrm{QT}_{2}$. The anisotropic $\mathrm{AO}$ interactions in the crystallographic planes cannot be realized with any other AWs, since the corresponding elasto-optic coefficients are zero. The EEC for the 
type $V I I I$ of $\mathrm{AO}$ interactions with the $\mathrm{AW}_{\mathrm{QT}_{1}}$ in the $a b$ plane can be written as

$$
p_{e f}^{(V I I I)}=p_{44} \cos (\theta-\alpha),
$$

where the AW propagates at the angles $0 \mathrm{deg}<\theta<V_{1}$ and $V_{2}<\theta<90 \mathrm{deg}$, and $\alpha$ denotes the angle between the $a$ axis and the wave vector of the incident optical wave. For the type $I X$ of AO interactions of the $\mathrm{AW} \mathrm{QT}_{2}$ in the $a c$ plane, the EEC is given by

$$
p_{e f}^{(I X)}=p_{66} \cos \theta \sin \alpha+p_{44} \sin \theta \cos \alpha .
$$

In case of the AW propagation angles $V_{1}<\theta<V_{2}$, the type $I X$ of $\mathrm{AO}$ interactions with the $\mathrm{AW}_{2}$ in the $a b$ plane is again described by Eq. (24).

\section{Results and discussion}

The AOFM anisotropy for the type $I$ of AO interactions in the ADP and KDP crystals is illustrated in Fig. 4. Consideration of the non-orthogonality effect in the crystallographic plane $a b$ changes notably the angular behaviour of the AOFM for the both crystals (cf. panels (b) and (d) in Fig. 4). However, for the $a c$ plane the non-orthogonality of AWs influences the AOFM anisotropy only for the ADP crystals (Fig. 4a). On the contrary, the AOFMs for the KDP crystals found under conditions of accounting for or neglecting by the AW non-orthogonality behave almost identically with changing $\theta$ angle (see Fig. 4c). This fact can be explained when examining Eqs. (4) and (5) and the elasto-optic coefficients $p_{12}$ and $p_{13}$ for the both crystals. In particular, the parameters $p_{12}$ and $p_{13}$ are almost the same for KDP and differ notably for ADP.
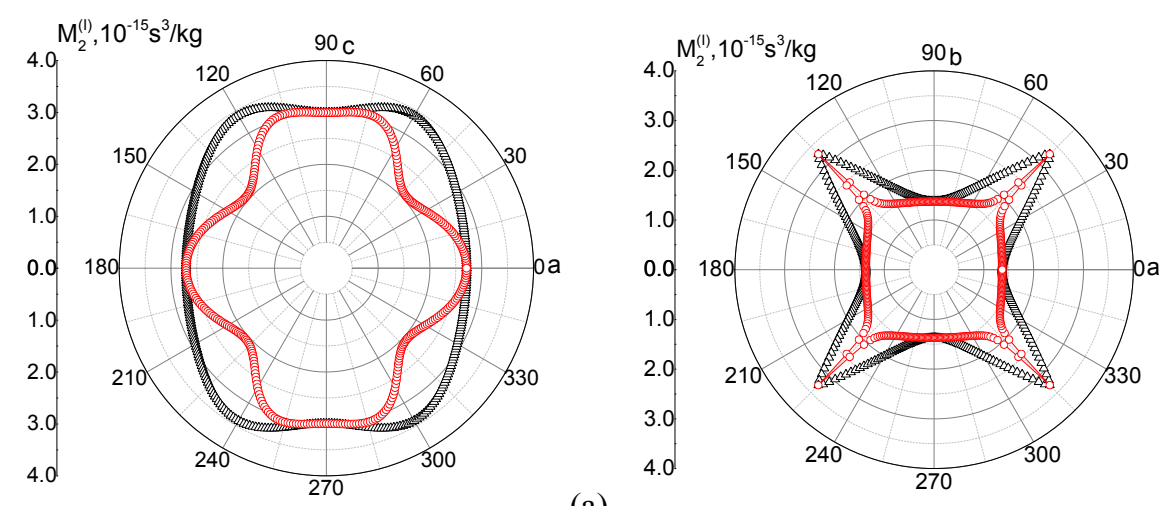

(a)
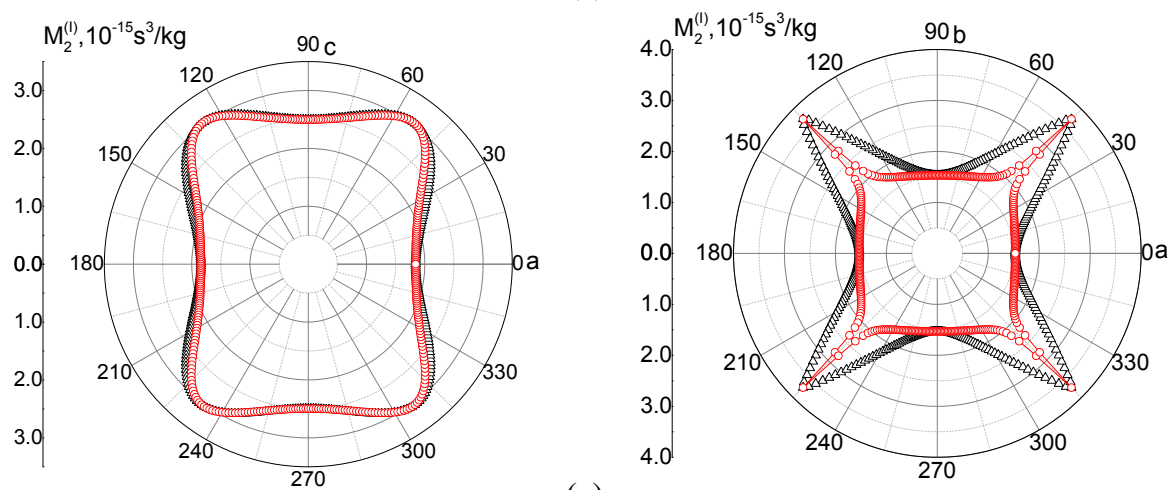

(c)

Fig. 4. Dependences of AOFM on the angle $\theta$ for the type $I$ of $A O$ interactions in the $a c(a, c)$ and $a b(b, d)$ planes for $\operatorname{ADP}(a, b)$ and $\operatorname{KDP}(c, d)$ crystals: open triangles and circles correspond respectively to neglecting and taking the AW non-orthogonality into account. 
The maximal AOFM value for the ADP crystals peculiar for the type $I$ of AO interactions is equal to $3.3 \times 10^{-15} \mathrm{~s}^{3} / \mathrm{kg}$. It is reached at the angles $\theta=45,135,225$ and 315 deg in the $a b$ plane. Since this maximum is very sharp, it would be more convenient from the practical viewpoint to deal with the interaction geometry in the $a c$ plane ( $\theta=90$ or $180 \mathrm{deg}$ ). The AOFM under these conditions is only a little smaller, $3.0 \times 10^{-15} \mathrm{~s}^{3} / \mathrm{kg}$. The maximal AOFM for the KDP crystals $\left(3.7 \times 10^{-15} \mathrm{~s}^{3} / \mathrm{kg}\right)$ can be achieved in the $a b$ plane at $\theta=45,135,225$ and $315 \mathrm{deg}$. Only slightly lower AOFM value, $3.0 \times 10^{-15} \mathrm{~s}^{3} / \mathrm{kg}$, can be reached at somewhat better practical conditions $\theta=53,127,233$ and $307 \mathrm{deg}$ in the ac plane.
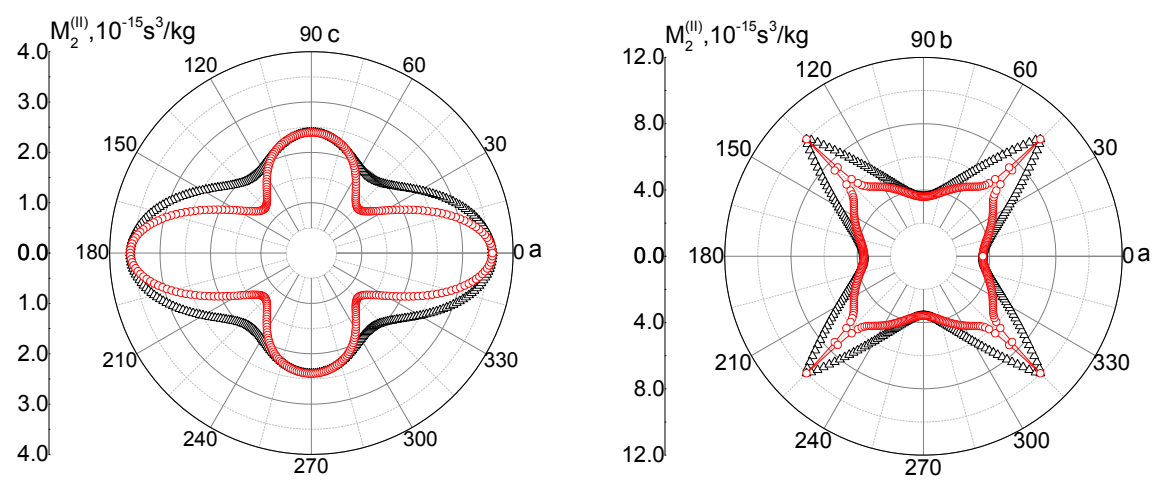

(a)

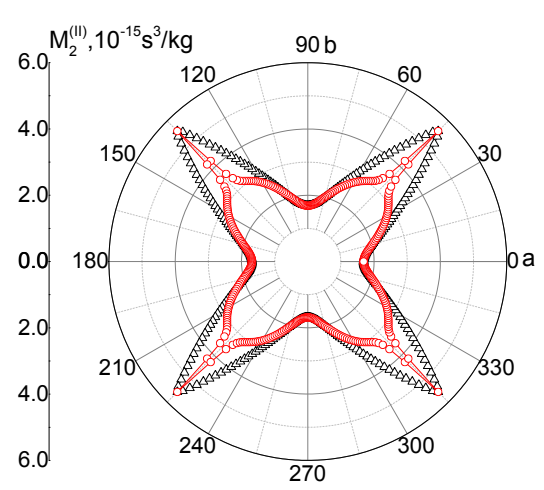

(b)

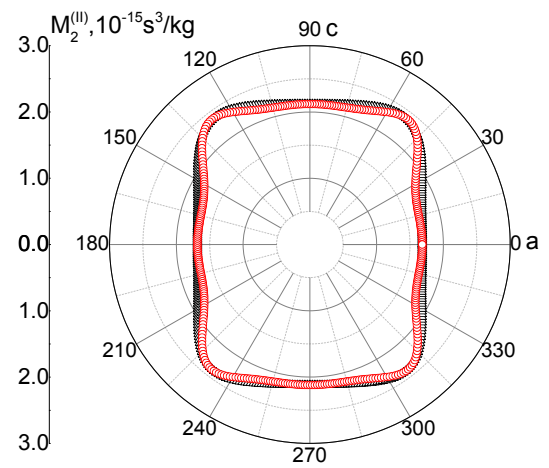

(c)

(d)

Fig. 5. Dependences of AOFM on the angle $\theta$ for the type // of AO interactions in the $a c(a, c)$ and $a b(b, d)$ planes for $\operatorname{ADP}(a, b)$ and $\operatorname{KDP}(c, d)$ crystals: open triangles and circles correspond respectively to neglecting and accounting for AW non-orthogonality.

The AOFM anisotropy at the type $I I$ of AO interactions shown in Fig. 5 is similar to that found for the type $I$. Namely, the AOFM anisotropies for ADP in the $a c$ plane differs noticeably under the conditions of accounting for and neglecting by the AW non-orthogonality, although they are almost the same for the KDP (cf. Fig. 5a with Fig. 5c). Such behaviour for the KDP crystals follows from close values of the elasto-optic coefficients $p_{11}, p_{13}, p_{31}$ and $p_{33}$ included into Eqs. (8) and (9). The difference among these coefficients is more pronounced for the ADP crystals. The anisotropy of AOFM in the $a b$ plane is caused mainly by the anisotropy of AW slowness (see Fig. 5b, d). The maximal AOFM for the ADP crystals is equal to $10.0 \times 10^{-15} \mathrm{~s}^{3} / \mathrm{kg}$, being achieved in the $a b$ plane at $\theta=45,135,225$ and $315 \mathrm{deg}$. The maximal AOFM value for the KDP crystals, $5.6 \times 10^{-15} \mathrm{~s}^{3} / \mathrm{kg}$, is reached under the same conditions.

In case of the type III of AO interactions in the $a c$ plane, the AOFM calculated with consideration of the AW non-orthogonality is higher than that derived when disregarding it (see 
Fig. 6a). However, the AOFM of KDP in the $a c$ plane calculated when the non-orthogonality effect is neglected is negligibly small, when compared with that calculated with taking the effect into account (see Fig. 6c). Let us remind that the elasto-optic tensor components $p_{12}=0.249 \pm 0.013$ and $p_{13}=0.242 \pm 0.012$ for KDP are almost the same, especially if one takes their inevitable experimental errors into account. Then Eq. (12) can be rewritten as $p_{e f}^{(I I I)}=\left(p_{12}-p_{13}\right) \sin 2 \theta \approx 0$. This is the reason why the AOFM for KDP in the $a c$ plane is almost equal to zero when the AW non-orthogonality is not considered. It follows from Eq. (13) that, under the condition $p_{12} \approx p_{13}$, the EEC can be rewritten as $p_{e f}^{(I I I)} \approx p_{12} \cos (\zeta-\theta)$. Hence, accounting for the angle of nonorthogonality in the KDP crystals leads to nonzero AOFM value in the crystallographic plane $a c$. The mentioned elasto-optic coefficient for the ADP crystals differs almost as twice, whereas the angle of non-orthogonality is somewhat higher than that for the KDP crystals. This results in decreasing AOFM in the $a c$ plane for ADP, when the deviation of $\mathrm{AW}$ polarization from the purely transverse types is considered. Neglecting by the angle of non-orthogonality in the $a b$ plane for the both crystals leads to a critical decrease in the AOFM (see Fig. 6b, d), since the elasto-optic coefficients $p_{11}$ and $p_{12}$ for the ADP and KDP crystals are close to each other, while the coefficient $p_{66}$ is very small. As a result, the $p_{e f}^{(I I I)}$ parameter given by Eq. (14) is small enough. It follows from Eq. (15) that accounting for the angle of non-orthogonality imposes increasing AOFM for the both crystals in the $a b$ plane. The maximal AOFM value for ADP $\left(6.9 \times 10^{-15} \mathrm{~s}^{3} / \mathrm{kg}\right)$ is reached in the $a b$ plane at $\theta=23,67,113,157,203,247,293$ and $337 \mathrm{deg}$. The maximal AOFM for KDP $\left(5.1 \times 10^{-15} \mathrm{~s}^{3} / \mathrm{kg}\right)$ is reached in the same plane at $\theta=20,70,110,160,200,250,290$ and $340 \mathrm{deg}$.

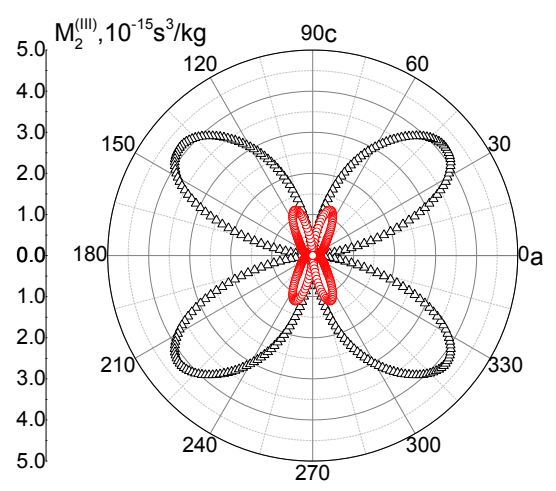

(a)
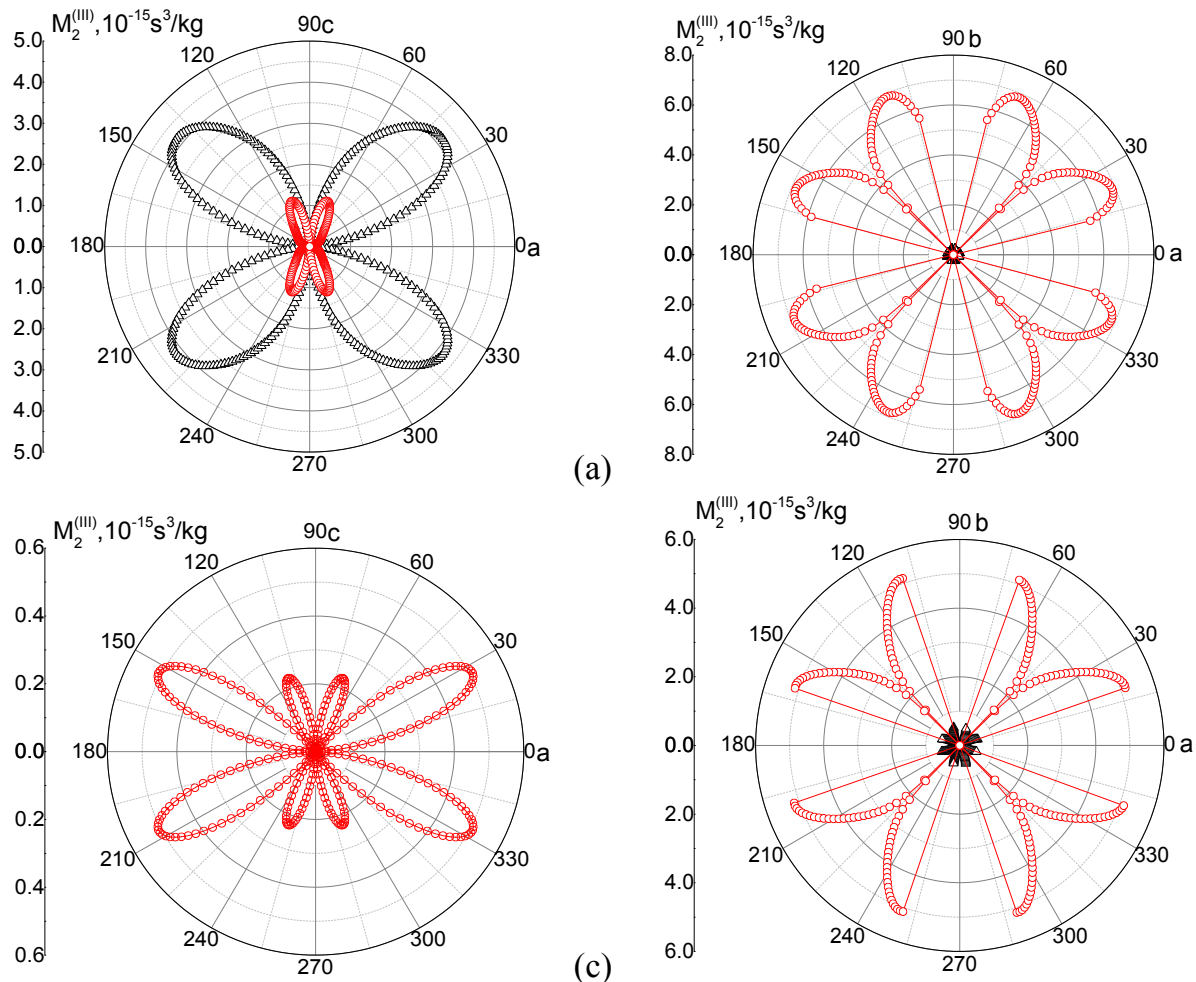

(b)

(c)

(d)

Fig. 6. Dependences of AOFM on the angle $\theta$ for the type III of AO interactions in the $a c(a, c)$ and $a b$ (b, d) planes for $\operatorname{ADP}(a, b)$ and KDP (c, d) crystals: open triangles and circles correspond respectively to neglecting by and accounting for AW non-orthogonality.

Ukr. J. Phys. Opt. 2018, Volume 19, Issue 4 
For the type $I V$ of AO interactions, the behaviour of AOFM (see Fig. 7) is similar to that calculated for the type III. However, the EEC for the $a b$ plane is equal to zero (see Eq. (18)) when the non-orthogonality is neglected (see Fig. 7b, d). On the other hand, consideration of this effect leads to deviation of the EEC from zero, according to Eq. (19). The maximal AOFM value for the ADP crystals, $1.4 \times 10^{-15} \mathrm{~s}^{3} / \mathrm{kg}$, is achieved in the $a b$ plane at $\theta=27,63,117,153,207,243,297$ and 333 deg. For KDP crystals, we have the maximal AOFM value $1.8 \times 10^{-15} \mathrm{~s}^{3} / \mathrm{kg}$ in the same interaction plane at $\theta=25,65,115,155,205,245,295$ and $335 \mathrm{deg}$.

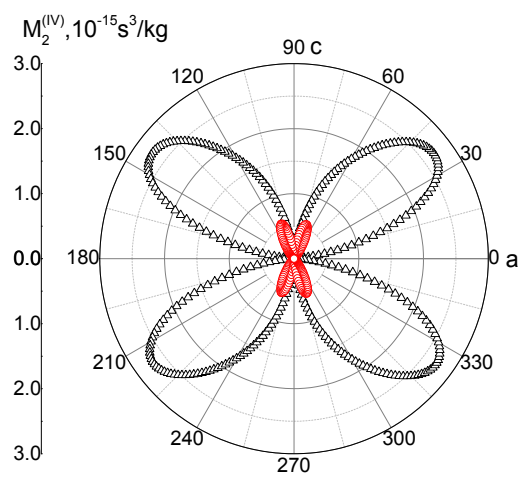

(a)
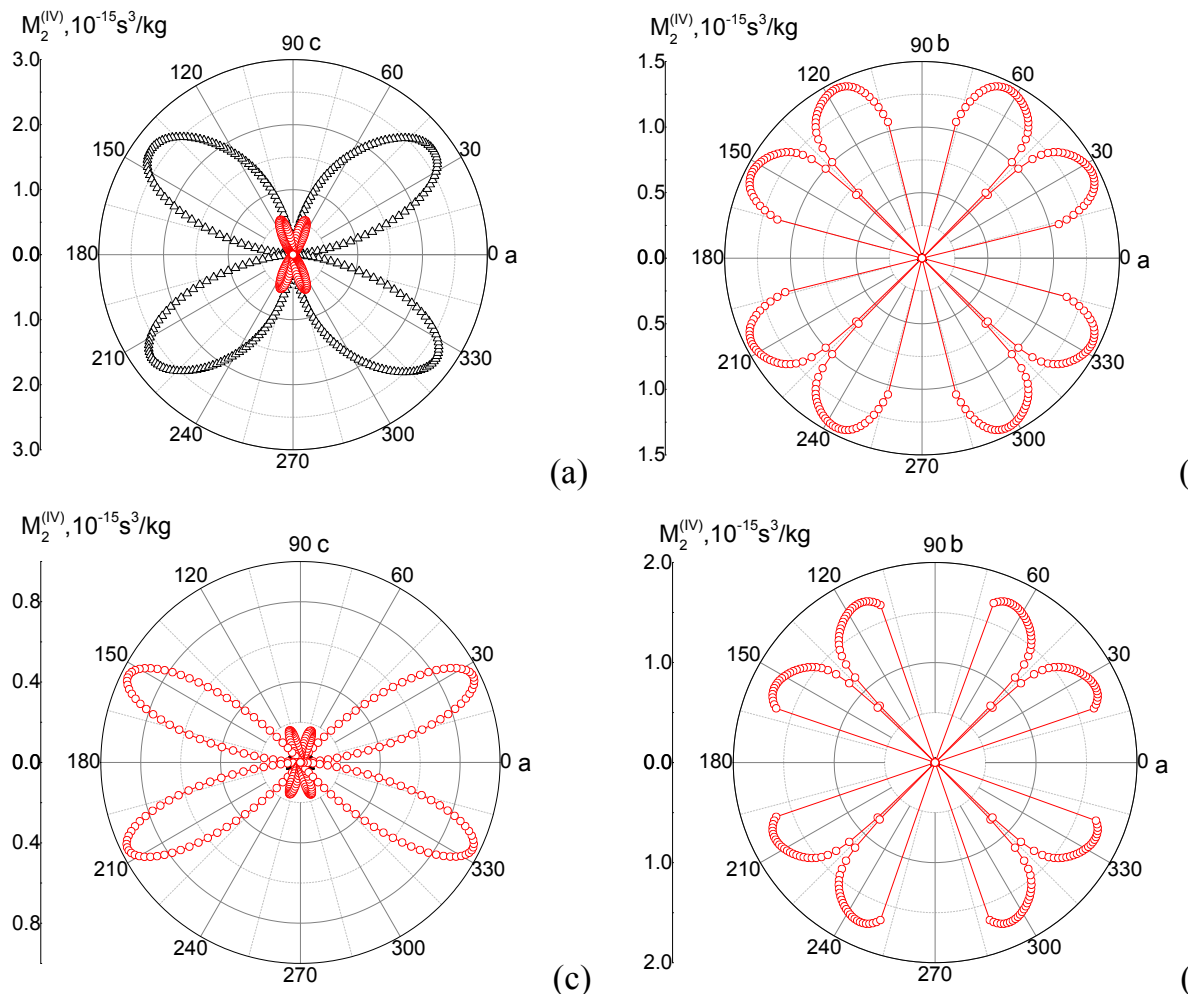

(b)

(c)

(d)

Fig. 7. Dependences of AOFM on the angle $\theta$ for the type $I V$ of $A O$ interactions in the $a c(a, c)$ and $a b(b, d)$ planes for $\operatorname{ADP}(a, b)$ and $\operatorname{KDP}(c, d)$ crystals: open triangles and circles correspond respectively to neglecting and accounting for AW non-orthogonality.

The types $V$ and $V I$ of $\mathrm{AO}$ interactions can be realized only in the crystallographic plane $a b$. Then the angular behaviours of the AOFM for the both crystals are similar (Fig. 8). Almost a zero AOFM value obtained when the non-orthogonality is neglected is caused by close elasto-optic coefficients that define the EEC (see Eqs. (20)-(23)). The maximal AOFM values at the type $V$ of AO interactions are equal to $5.2 \times 10^{-15} \mathrm{~s}^{3} / \mathrm{kg}$ and $5.1 \times 10^{-15} \mathrm{~s}^{3} / \mathrm{kg}$. They are reached in the $a b$ plane at $\theta=13,77,103,166,193,257,283$ and 346 deg for ADP and at $\theta=18,71,108$, $162,198,252,288$ and $341 \mathrm{deg}$ for KDP. Concerning the type VI of AO interactions, we obtain the maximal AOFM values equal to $1.0 \times 10^{-15} \mathrm{~s}^{3} / \mathrm{kg}$ for ADP (at $\theta=13,77,103,166$, $193,257,283$ and $346 \mathrm{deg}$ ) and $1.6 \times 10^{-15} \mathrm{~s}^{3} / \mathrm{kg}$ for KDP (at $\theta=18,71,108,162,198,252,288$ and $341 \mathrm{deg}$ ).

Let us consider the anisotropic AO diffraction in the ADP and KDP crystals. Fig. 9 shows the dependences of AOFM on the angle $\alpha+\gamma$. We remind that $\alpha$ is the angle of incidence of the 
light wave (i.e., the angle between the wave vector of the incident optical wave and the $a$ axis) and $\gamma$ the diffraction angle (i.e., the angle between the wave vectors of the incident and diffracted optical waves). The type VIII of AO interactions can be realized in the crystallographic plane $a b$. The maximal AOFM value for the ADP crystals, $2.1 \times 10^{-15} \mathrm{~s}^{3} / \mathrm{kg}$ (see Fig. 9a), which is peculiar for the type VIII of AO interactions, is reached at $\alpha=90 \mathrm{deg}, \alpha+\gamma=82$ or $98 \mathrm{deg}$, and $\gamma=+8$ or -8 deg. The maximal AOFM for the KDP crystals (see Fig. 9b) is reached under the same conditions, although its value is somewhat lower, $1.8 \times 10^{-15} \mathrm{~s}^{3} / \mathrm{kg}$.

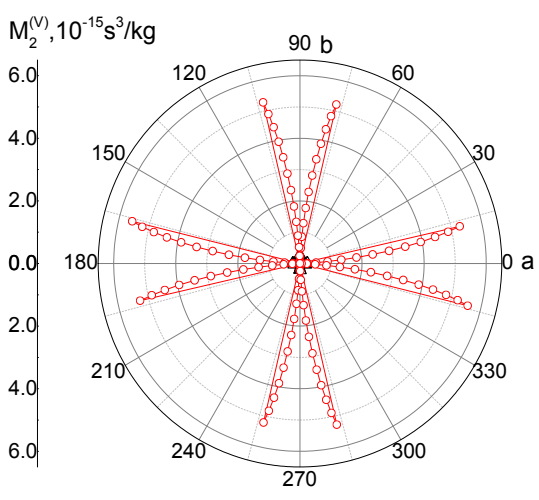

(a)
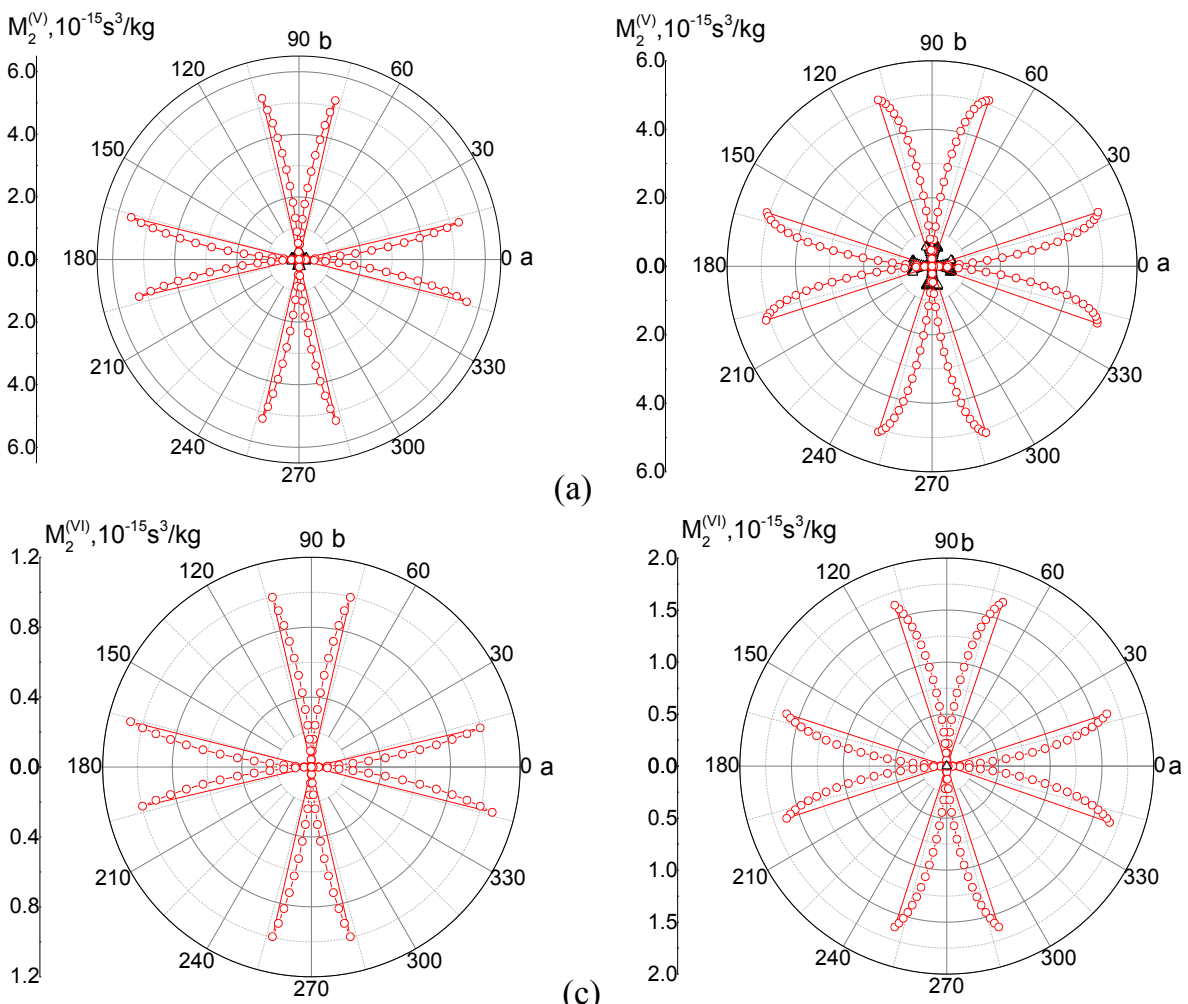

(b)

(c)

(d)

Fig. 8. Anisotropy of AOFM for the types $V(a, b)$ and $V I(c, d)$ of $A O$ interactions for ADP $(a, c)$ and KDP (b, d) crystals.

Using the type $I X$ of AO interactions (see Fig. 9c, d), we obtain the maximal AOFM $9.5 \times 10^{-15} \mathrm{~s}^{3} / \mathrm{kg}$ for the ADP crystals. It is reached at almost collinear AO interactions, i.e. at $\alpha=90 \mathrm{deg}$ and $\alpha+\gamma=89$ or $91 \mathrm{deg}$, and $\gamma=+1$ or $-1 \mathrm{deg}$. The maximal AOFM for the KDP crystals, $5.3 \times 10^{-15} \mathrm{~s}^{3} / \mathrm{kg}$, is achieved under the same conditions.

Let us examine the collinear diffraction as a particular case of anisotropic diffraction. The collinear diffraction can be implemented at $\gamma=0$ or $90 \mathrm{deg}$. For the type VIII of AO interactions (see Fig. 10a), the maximal AOFM for the ADP crystals is equal to $0.5 \times 10^{-15} \mathrm{~s}^{3} / \mathrm{kg}$. This value is peculiar for the $a b$ plane at $\alpha=68,112,248$ and $292 \mathrm{deg}$. The maximal AOFM for the KDP crystals (see Fig. 10b) is the same and occurs under identical conditions. Finally, the maximal AOFM for the ADP crystals and the type $I X$ of AO interactions in the ac plane is equal to $4.4 \times 10^{-15} \mathrm{~s}^{3} / \mathrm{kg}$ at $\alpha=41,139,221$ and $319 \mathrm{deg}$. It is equal to $1.2 \times 10^{-15} \mathrm{~s}^{3} / \mathrm{kg}$ for KDP and occurs at $\alpha=38,142,218$ and $322 \mathrm{deg}$. 

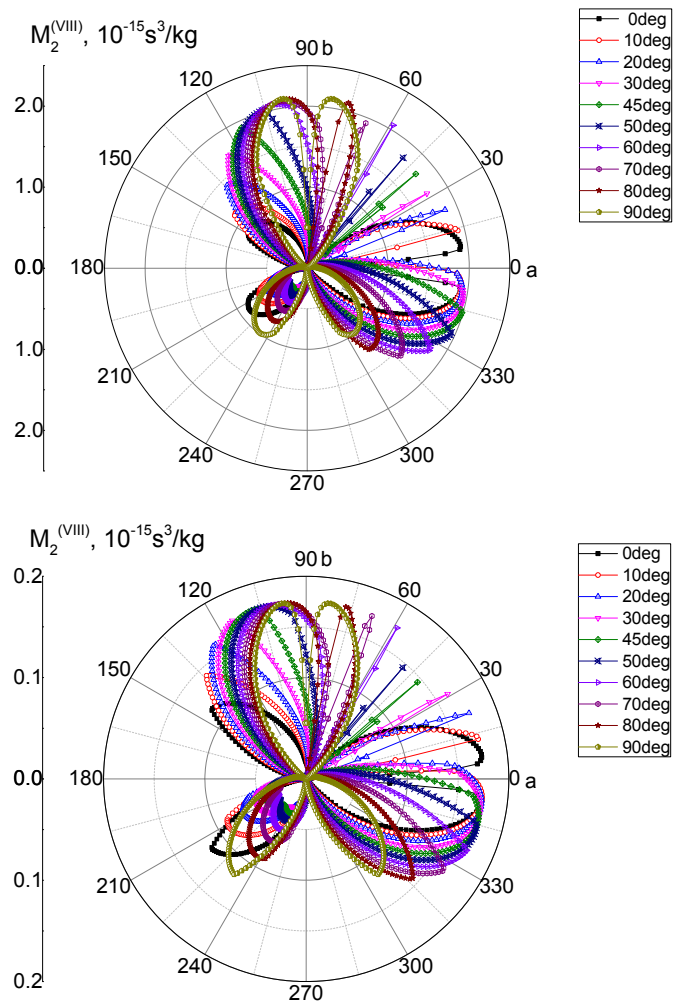

(a)

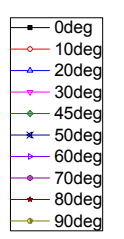

(b)
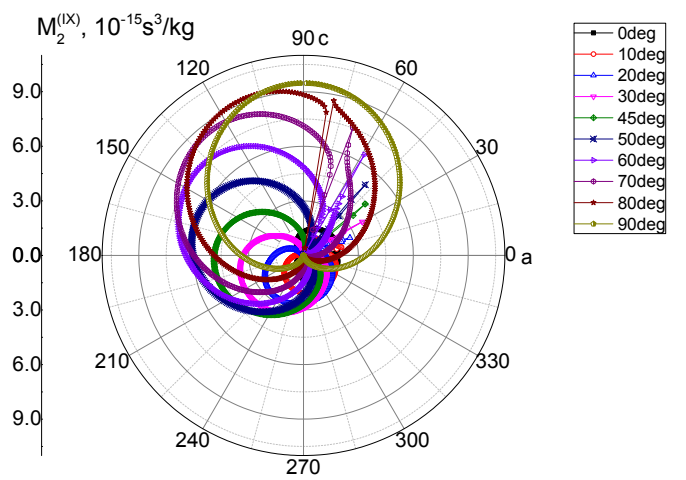

(c)
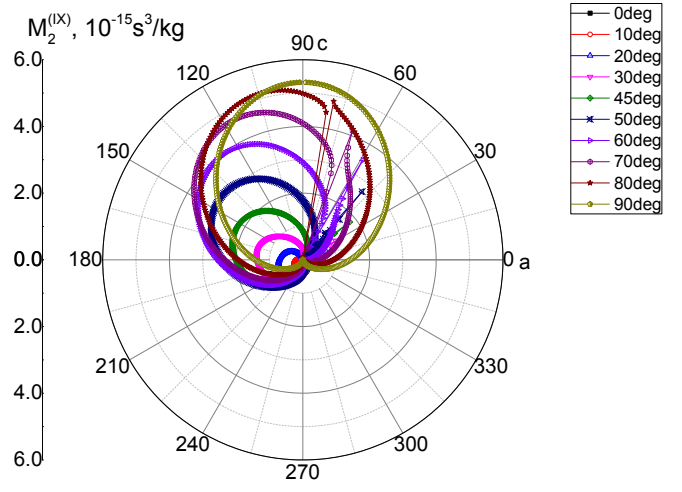

(d)

Fig. 9. Dependences of AOFM for the types VIII (a, b) and IX (c, d) of AO interactions in ADP (a, c) and KDP (b, d) crystals on the angle $\alpha+\gamma$, as calculated at different incidence angles $\alpha$ of optical wave. 


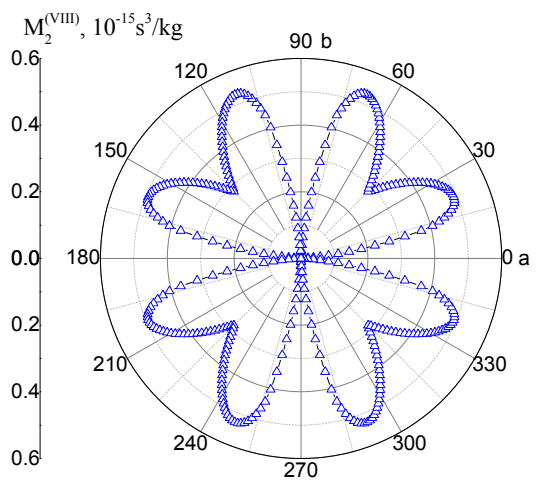

(a)
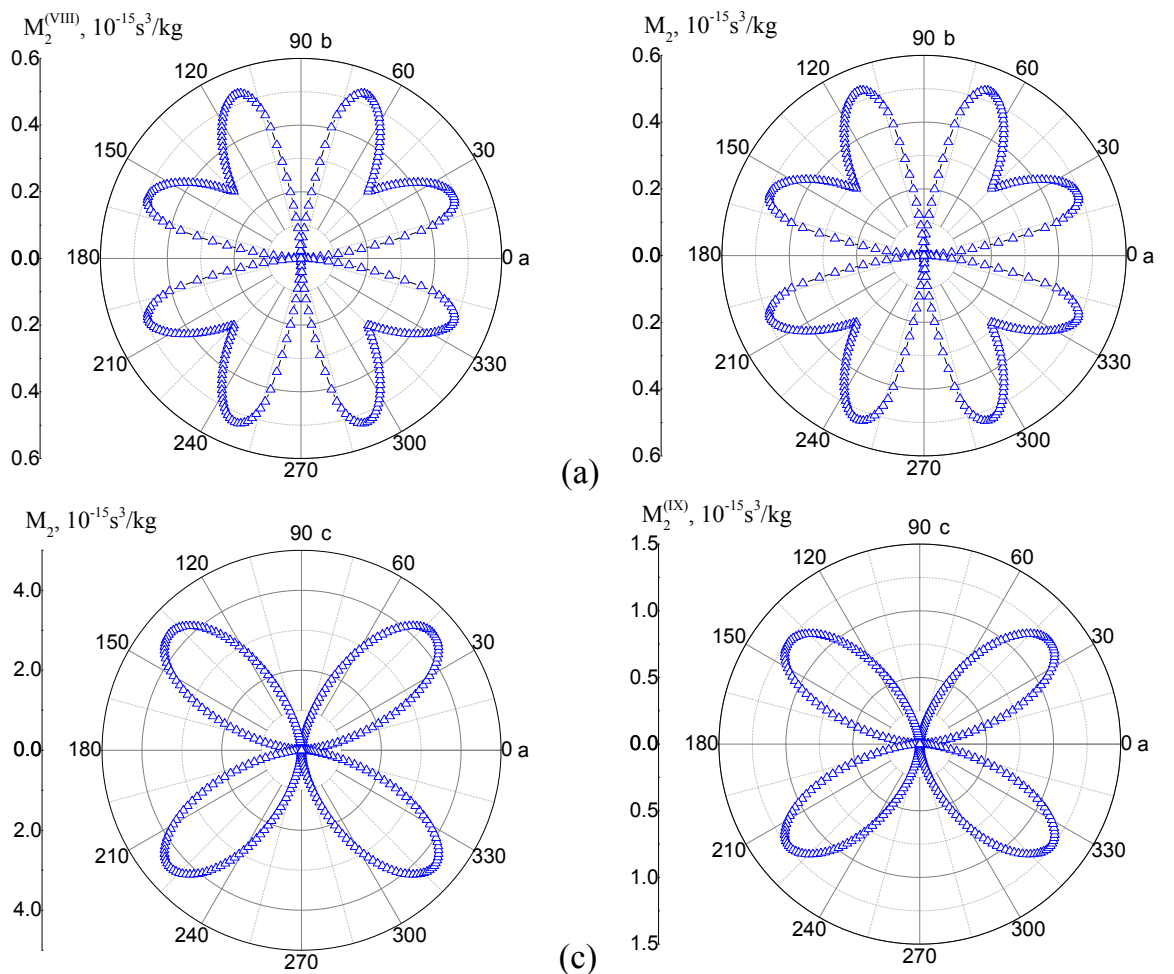

(b)

Fig. 10. Dependences of AOFM on the angle $\alpha$ at the collinear diffraction at the types $V I I I(a, b)$ and IX (c, d) of $\mathrm{AO}$ interactions in $\operatorname{ADP}(a, c)$ and KDP (b, d) crystals.

Table 1. Maximal AOFM values calculated for the ADP and KDP crystals at different types of isotropic $\mathrm{AO}$ interactions.

\begin{tabular}{|c|c|c|c|c|c|c|}
\hline $\begin{array}{l}\text { Type of } \mathrm{AO} \\
\text { interactions }\end{array}$ & $I$ & $I I$ & III & $I V$ & $V$ & $V I$ \\
\hline \multicolumn{7}{|c|}{ KDP } \\
\hline $\begin{array}{l}\text { Angle } \theta, \\
\text { deg, and } \\
\text { interaction } \\
\text { plane }\end{array}$ & $\begin{array}{l}45, \quad 135, \\
225 \text { and } \\
315, \\
a b \text { plane }\end{array}$ & $\begin{array}{l}45, \quad 135, \\
225 \text { and } \\
315, \\
a b \text { plane }\end{array}$ & $\begin{array}{l}20, \\
110, \quad 160, \\
200, \quad 250, \\
290 \quad \text { and } \\
340, \\
a b \text { plane }\end{array}$ & $\begin{array}{l}25, \\
115, \quad 155, \\
205, \quad 245, \\
295 \quad \text { and } \\
335, \\
a b \text { plane }\end{array}$ & $\begin{array}{l}18, \quad 71, \\
108, \quad 162, \\
198, \quad 252, \\
288 \quad \text { and } \\
341, \\
a b \text { plane }\end{array}$ & $\begin{array}{l}18, \\
108, \quad 162, \\
198, \quad 252, \\
288 \quad \text { and } \\
341, \\
a b \text { plane }\end{array}$ \\
\hline $\begin{array}{l}\text { AOFM, } \\
10^{-15} \mathrm{~s}^{3} / \mathrm{kg}\end{array}$ & 3.7 & 5.6 & 5.1 & 1.8 & 5.1 & 1.6 \\
\hline \multicolumn{7}{|c|}{ ADP } \\
\hline $\begin{array}{l}\text { Angle } \theta, \\
\text { deg, and } \\
\text { interaction } \\
\text { plane }\end{array}$ & $\begin{array}{l}45, \quad 135, \\
225 \text { and } \\
315, \\
a b \text { plane }\end{array}$ & $\begin{array}{l}45, \quad 135, \\
225 \text { and } \\
315, \\
a b \text { plane }\end{array}$ & $\begin{array}{l}23, \\
113, \\
207, \\
203, \\
293 \\
337, \\
a b \text { plane }\end{array}$ & $\begin{array}{l}27, \quad 63, \\
117, \quad 153, \\
207, \quad 243, \\
297 \quad \text { and } \\
333, \\
a b \text { plane }\end{array}$ & $\begin{array}{l}13, \\
103, \quad 166, \\
193, \quad 257, \\
283 \quad \text { and } \\
346, \\
a b \text { plane }\end{array}$ & $\begin{array}{l}13, \\
103, \\
163, \\
193,257, \\
283 \text { and } \\
346, \\
a b \text { plane }\end{array}$ \\
\hline $\begin{array}{l}\text { AOFM, } \\
10^{-15} \mathrm{~s}^{3} / \mathrm{kg}\end{array}$ & 3.3 & 10.0 & 6.9 & 1.4 & 5.2 & 1.0 \\
\hline
\end{tabular}

Ukr. J. Phys. Opt. 2018, Volume 19, Issue 4 
As seen from Table 1, the principal AOFM maximum for KDP at the isotropic diffraction amounts to $5.6 \times 10^{-15} \mathrm{~s}^{3} / \mathrm{kg}$. This value is achieved at the type $I I$ of AO interactions with the quasilongitudinal AW in the crystallographic plane $a b$. The principal AOFM maximum for ADP, $10.0 \times 10^{-15} \mathrm{~s}^{3} / \mathrm{kg}$, is reached for the same type of $\mathrm{AO}$ interactions and in the same interaction plane. Notice that this value is the highest AOFM found for all the types of AO interactions in the crystallographic planes for the both crystals.

Table 2. Maximal AOFM values for the ADP and KDP crystals at different types of anisotropic AO interactions.

\begin{tabular}{|c|c|c|c|c|}
\hline $\begin{array}{l}\text { Type of AO } \\
\text { interactions }\end{array}$ & VIII & $I X$ & $\begin{array}{c}\text { VIII } \\
\text { (collinear) }\end{array}$ & $\begin{array}{c}I X \\
\text { (collinear) }\end{array}$ \\
\hline \multicolumn{5}{|c|}{ KDP } \\
\hline $\begin{array}{l}\text { Angles } \alpha, \text { deg; } \\
\gamma, \text { deg, and } \\
\text { interaction plane }\end{array}$ & $\begin{array}{c}90 ;+8 \text { or }-8 \\
a b \text { plane }\end{array}$ & $\begin{array}{c}90 ;+1 \text { or }-1, \\
a c \text { plane }\end{array}$ & $\begin{array}{c}68,112,248 \text { and } \\
292 ; 0, \\
a b \text { plane }\end{array}$ & $\begin{array}{c}38,142,218 \text { and } \\
322 ; 0, \\
a c \text { plane }\end{array}$ \\
\hline $\begin{array}{l}\text { AOFM, } \\
10^{-15} \mathrm{~s}^{3} / \mathrm{kg}\end{array}$ & 1.8 & 5.3 & 0.5 & 1.2 \\
\hline \multicolumn{5}{|c|}{ ADP } \\
\hline $\begin{array}{l}\text { Angles } \alpha \text {, deg; } \\
\gamma, \text { deg, and } \\
\text { interaction plane }\end{array}$ & $\begin{array}{c}90 ;+8 \text { or }-8 \\
a b \text { plane }\end{array}$ & $\begin{array}{c}90 ;+1 \text { or }-1 \\
a c \text { plane }\end{array}$ & $\begin{array}{c}68,112,248 \text { and } \\
292 ; 0, \\
a b \text { plane }\end{array}$ & $\begin{array}{c}41,139,221 \text { and } \\
319 ; 0, \\
a c \text { plane }\end{array}$ \\
\hline $\begin{array}{l}\text { AOFM, } \\
10^{-15} \mathrm{~s}^{3} / \mathrm{kg}\end{array}$ & 2.1 & 9.5 & 0.5 & 4.4 \\
\hline
\end{tabular}

In case of the anisotropic diffraction (see Table 2), the highest AOFM value can be reached at the type $I X$ of $\mathrm{AO}$ interactions with the $\mathrm{AW} \mathrm{QT}_{2}$ in the $a c$ plane. The highest AOFMs are equal to $5.3 \times 10^{-15} \mathrm{~s}^{3} / \mathrm{kg}$ and $9.5 \times 10^{-15} \mathrm{~s}^{3} / \mathrm{kg}$ for $\mathrm{KDP}$ and $\mathrm{ADP}$, respectively. The latter value is comparable with the highest one achieved at the isotropic diffraction. The collinear diffraction is also characterized by the highest AOFMs at the type $I X$ of AO interactions. These values are equal to $1.2 \times 10^{-15} \mathrm{~s}^{3} / \mathrm{kg}$ and $4.4 \times 10^{-15} \mathrm{~s}^{3} / \mathrm{kg}$ for KDP and ADP, respectively.

\section{Conclusions}

In the present work we have derived the analytical relations for the EEC with accounting for the angle of non-orthogonality of AW polarization in case of the crystals belonging to the symmetry group $\overline{4} 2 \mathrm{~m}$. The same relations are valid for the other point groups of tetragonal system, such as 4/mmm, 422 and $4 \mathrm{~mm}$. The above relations can also be used for the point symmetry groups $6 / \mathrm{mmm}, 6 \mathrm{~mm}, 622$ and $\overline{6} \mathrm{~m} 2$ of hexagonal system, as well as for the Curie symmetry groups $\infty 2$, $\infty \mathrm{mm}$ and $\infty / m$, with taking into account the additional relations $p_{66}=\left(p_{11}-p_{12}\right) / 2$ and $C_{66}=\left(C_{11}-C_{12}\right) / 2$ valid for the latter groups. We have analyzed the anisotropy of AOFM for the KDP and ADP crystals within their crystallographic planes in the cases when the effect of nonorthogonality of AW polarizations is neglected by or accounted for. We have found that consideration of the effect mentioned above changes significantly the AOFM value. This concerns almost all the types of AO interactions, except for the types $I$ and $I I$ of interactions with the quasi-longitudinal AWs in KDP. Moreover, in some cases the non-orthogonality of AW polarizations can lead to appearance of AO interactions, although this interaction is forbidden at the zero angle of nonorthogonality. The latter fact concerns the types $I V$ and $V I$ of interactions with the $\mathrm{AWs}_{\mathrm{Q}} \mathrm{QT}_{1}$ and $\mathrm{QT}_{2}$, respectively. 
The geometries of AO diffraction at which the maximal AOFM values have to be observed are obtained for all of the nine types of $\mathrm{AO}$ interactions, including the particular case of collinear diffraction. We have demonstrated that the principal AOFM maximum for the KDP crystals is equal to $5.6 \times 10^{-15} \mathrm{~s}^{3} / \mathrm{kg}$ at the isotropic diffraction. The corresponding value for the ADP crystals amounts to $10.0 \times 10^{-15} \mathrm{~s}^{3} / \mathrm{kg}$. Note that the latter value represents the highest AOFM calculated for all the types of $\mathrm{AO}$ interactions in the crystallographic planes for the both crystals. It can be achieved at the type II of AO interactions with the quasi-longitudinal $\mathrm{AW}$ in the crystallographic plane $a b$. The highest AOFM value for the case of anisotropic AO diffraction can be reached at the type $I X$ of interactions with the $\mathrm{AW} \mathrm{QT}_{2}$ in the $a c$ plane. It is equal to $5.3 \times 10^{-15} \mathrm{~s}^{3} / \mathrm{kg}$ and $9.5 \times 10^{-15} \mathrm{~s}^{3} / \mathrm{kg}$ for KDP and ADP, respectively. The latter value is comparable with the highest AOFM achieved at the isotropic diffraction. The collinear diffraction is also characterized by the highest AOFMs at the type $I X$ of $\mathrm{AO}$ interactions. These values are equal respectively to $1.2 \times 10^{-15} \mathrm{~s}^{3} / \mathrm{kg}$ and $4.4 \times 10^{-15} \mathrm{~s}^{3} / \mathrm{kg}$ for KDP and ADP. Finally, the ADP crystals reveal higher AOFMs at any of the isotropic, anisotropic or collinear AO diffractions, if compared with the KDP crystals.

\section{References}

1. Shaskolskaya M P. Acoustic crystals. Moscow: Nauka (1982).

2. Yano $\mathrm{T}$ and Watanabe A, 1974. Acoustooptic figure of merit of $\mathrm{TeO}_{2}$ for circularly polarized light. J. Appl. Phys. 45: 1243-1245.

3. Vlokh R, Dyachok Ya, Krupych O, Burak Ya, Martunyuk-Lototska I, Andrushchak A and Adamiv V, 2003. Study of laser-induced damage of borate crystals. Ukr. J. Phys. Opt. 4: 101104.

4. Komatsu R, Sugawara T, Sassa K, Sarukura N, Liu Z, Izumida S, Segawa Y, Uda S, Fukuda T and Yamanouchi K, 1997. Growth and ultraviolet application of $\mathrm{Li}_{2} \mathrm{~B}_{4} \mathrm{O}_{7}$ crystals: Generation of the fourth and fifth harmonics of $\mathrm{Nd}_{2} \mathrm{Y}_{3} \mathrm{Al}_{5} \mathrm{O}_{12}$ lasers. Appl. Phys. Lett. 70: 3492-3494.

5. Martynyuk-Lototska I, Mys O, Dudok T, Adamiv V, Smirnov Y and Vlokh R, 2008. Acoustooptic interaction in $\alpha-\mathrm{BaB}_{2} \mathrm{O}_{4}$ and $\mathrm{Li}_{2} \mathrm{~B}_{4} \mathrm{O}_{7}$ crystals. Appl. Opt. 47: 3446- 3454.

6. Martynyuk-Lototska I, Mys O, Krupych O, Adamiv V, Burak Ya, Vlokh R and Schranz W, 2004. Elastic, piezooptic and acoustooptic properties of borate crystals $\left(\mathrm{BaB}_{2} \mathrm{O}_{4}, \mathrm{Li}_{2} \mathrm{~B}_{4} \mathrm{O}_{7}\right.$ and $\mathrm{CsLiB}_{6} \mathrm{O}_{10}$ ). Integrated Ferroelectrics. 63: 99-103.

7. Krupych O, Mys O, Kryvyy T, Adamiv V, Burak Y and Vlokh R, 2016. Photoelastic properties of lithium tetraborate crystals. Appl. Opt. 55: 10457-10462.

8. Mys O, Krupych O and Vlokh R, 2018. Anisotropy of acousto-optic figure of merit in lithium tetraborate crystals. J. Mod. Opt. 65: 1486-1494.

9. Coudreau S, Kaplan D and Tournois P, 2006. Ultraviolet acousto-optic programmable dispersive filter laser pulse shaping in KDP. Opt. Lett. 31: 1899-1901.

10. Dekemper E, Fussen D, Van Opstal B, Vanhamel J, Pieroux D, Vanhellemont F, Mateshvilia N, Franssens G, Voloshinov V, Janssen C and Elandaloussi H, 2014. ALTIUS: a spaceborne AOTF-based UV-VIS-NIR hyperspectral imager for atmospheric remote sensing. Proc. SPIE. 9241: 92410L.

11. Gupta N and Voloshinov V, 2004. Hyperspectral imager, from ultraviolet to visible, with a KDP acousto-optic tunable filter. Appl. Opt. 43: 2752-2759.

12. Gupta N and Voloshinov V, 2014. Spectral characterization in deep UV of an improved imaging KDP acousto-optic tunable filter. J. Opt. 16: 035301-035310. 
13. Mys $\mathrm{O}$, Krupych $\mathrm{O}$ and Vlokh R, 2017. Anisotropy of acoustooptic figure of merit in $\mathrm{KH}_{2} \mathrm{PO}_{4}$ crystals. Ukr. J. Phys. Opt. 18: 83-94.

14. Mys O, Kostyrko M, Smyk M, Krupych O and Vlokh R, 2014. Anisotropy of acoustooptic figure of merit in optically isotropic media. Appl. Opt. 53: 4616-4627.

15. Mys O, Kostyrko M, Smyk M, Krupych O and Vlokh R, 2014. Anisotropy of acoustooptic figure of merit for $\mathrm{TeO}_{2}$ crystals. 1. Isotropic diffraction. Ukr. J. Phys. Opt. 15: 132-154.

16. Mys O, Kostyrko M, Krupych O and Vlokh R, 2014. Anisotropy of acoustooptic figure of merit for $\mathrm{TeO}_{2}$ crystals. 2. Anisotropic diffraction. Ukr. J. Phys. Opt. 16: 38-60.

17. Mys O, Krupych $\mathrm{O}$ and Vlokh R, 2016. Anisotropy of an acousto-optic figure of merit for $\mathrm{NaBi}\left(\mathrm{MoO}_{4}\right)_{2}$ crystals. Appl. Opt. 55: 7941-7955.

18. Mys O, Kostyrko M, Krupych O and Vlokh R, 2015. Anisotropy of the acousto-optic figure of merit for $\mathrm{LiNbO}_{3}$ crystals: Isotropic diffraction. Appl. Opt. 54: 8176-8186.

19. Mys O, Krupych O, Kostyrko M and Vlokh R, 2016. Anisotropy of acousto-optic figure of merit for $\mathrm{LiNbO}_{3}$ crystals: Anisotropic diffraction. Erratum. Appl. Opt. 55: 9823-9829.

20. Mys O, Adamenko D, Krupych O and Vlokh R, 2018. Effect of deviation from purely transverse and longitudinal polarization states of acoustic waves on the anisotropy of acoustooptic figure of merit: The case of $\mathrm{Tl}_{3} \mathrm{AsS}_{4}$ crystals. Appl. Opt. 57: 8320-8330.

21. Pyle J R, 1966. Laser modulation using linear electro-optic crystals. Techn. Note PAD. 125, p. NASA N67-27128.

22. Marvin J. Handbook of optical materials. Boca Raton London, New York, Washington: Weber CRC Press LLC (2003).

23. Price W J and Huntington H B, 1950. Acoustical properties of anisotropic materials. Acoust. Soc. Amer. J. 22: 32-37.

24. Avakyants L P, Kiselev D F, Perelomova N V and Sugrej V I, 1983. Elastooptics of $\mathrm{KH}_{2} \mathrm{PO}_{4}$, $\mathrm{KD}_{2} \mathrm{PO}_{4}$ and $\mathrm{RbH}_{2} \mathrm{PO}_{4}$. Fiz. Tverd. Tela. 25: 580-582.

25. Balakshyi V I, Paryhyn V N and Chyrkov L E. Physical foundations of acoustooptics. Moscow: Radio and Communications (1985).

Mys O., Kostyrko M., Adamenko D. and Vlokh R. 2018. Anisotropy of acousto-optic figure of merit in tetragonal crystals with accounting for non-orthogonality of acoustic eigenwave polarizations. 1. The cases of $\mathrm{KH}_{2} \mathrm{PO}_{4}$ and $\mathrm{NH}_{4} \mathrm{H}_{2} \mathrm{PO}_{4}$ crystals Ukr.J.Phys.Opt. 19: 220 - 236. doi: $10.3116 / 16091833 / 19 / 4 / 220 / 2018$

Анотація. У роботі одержано аналітичні вирази для ефективних пружнооптичних коефіџієнтів з урахуванням неортогональності поляризаиії акустичних хвиль (АХ) у кристалах, що належать до груп симетрії 4/mmm, 422 і 4mm. Проаналізовано анізотропію коефіціснта акустооптичної (AO) якості для кристалів KDP i ADP в кристалографічних плочинах. Цю анізотропію одержано за умов, коли ефект неортогональності АХ знехтуваний або врахований. Показано, що належне врахування кута неортогональності $A X$ істотно змінюе величину коефіцієнта акустооптичної якості. Встановлено геометрії АOдифракиії, для яких можна одержати максимальні значення коефіцієнта акустооптичної

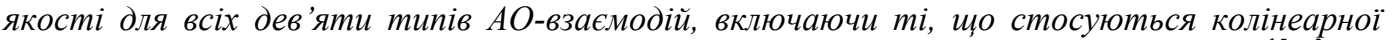
дифракиії. Продемонстровано, що найбільший максимум якості дорівнює $10,0 \times 10^{-15} c^{3} / \kappa 2 ~ i$ має місие для кристалів ADP. Його можна досягти для AO-взаємодій типу II із квазіпоздовжніми $A X$ у кристалографічній площині ab. Найвище значення коефічієнта акустоптичної якості, характерне для анізотропної AO-дифракиї в ADP, складає $9,5 \times 10^{-15} c^{3} / к 2$ і досягається для AO-взаємодій типу $I X$ із так званою $A X Q T_{2}$ у площині ас. Нарешті, найвищий коефіиієнт якості для випадку колінеарної дифракиії дорівнюе $4,4 \times 10^{-15} c^{3} / \kappa 2$ і також властивий кристалам ADP. 